\title{
Variation of Interpersonal Values Following Alcohol Withdrawal in Alcoholics Seeking Treatment: 12-Month Longitudinal Study*
}

\author{
Isabelle Boulze1,2\#, Michel Launay', Bertrand Nalpass,3 \\ ${ }^{1}$ Laboratory EA4556 Epsylon, Dynamics of Human Abilities \& Health Behaviors, CEPS Platform European \\ Methodology Platform for Non Pharmacological Interventions (NPIs), Department of Medicine, \\ Subject and Society Sciences, Sport Sciences, University of Montpellier, Montpellier, France \\ ${ }^{2}$ Addiction Treatment Unit, Hospital Caremeau, Nîmes, France \\ ${ }^{3}$ Inserm Département d'Information Scientifique et de Communication (DISC), Mission Inserm Associations, \\ Paris, France \\ Email: "isabelle.boulze@univ-montp3.fr
}

Received 24 November 2015; accepted 8 January 2016; published 11 January 2016

Copyright $(\subset 2016$ by authors and Scientific Research Publishing Inc.

This work is licensed under the Creative Commons Attribution International License (CC BY).

http://creativecommons.org/licenses/by/4.0/

(c) (i) Open Access

\begin{abstract}
We performed a community research program in order to analyze the evolution of interpersonal values following alcohol withdrawal in alcoholics attending to a self-help group. The Gordon questionnaire on interpersonal values was administered every 3 months during one year to 145 individuals having recently stopped drinking. At baseline, scores of 5 interpersonal categories (dependence, conformism, consideration, independence, kindness) were in the medium interval of usual values while that of command category was low, specifically in men. Values of conformism and independence increased according to time while those of dependence and consideration decreased but the differences were significant only in those who remained abstinent all along the observation period. In those who relapsed, there were no modifications; however, sharing these values might have allowed these subjects to be less isolated. We will describe in details the nature of these evolutions.
\end{abstract}

\section{Keywords}

Alcoholism, Abstinence, Interpersonal Values, Community Research

\footnotetext{
*This study was done in collaboration with the following support organisations for alcohol-dependent subjects (in alphabetic order): Alcooliques anonymes, Alcool Assistance, Alcool Ecoute joie et santé, Croix Bleue, Les amis de la santé, Vie libre.

"Corresponding author.
}

How to cite this paper: Boulze, I., Launay, M., \& Nalpas, B. (2016). Variation of Interpersonal Values Following Alcohol Withdrawal in Alcoholics Seeking Treatment: 12-Month Longitudinal Study. Psychology, 7, 19-27. 


\section{Introduction}

When attempting to prolong abstinence, alcohol-dependent subjects face a psychological challenge they have already encountered before the cessation of alcohol intake: That of isolation—or solitude—as described by Fouquet (1963) and Rainaut (1973). According to Fouquet (1963), isolation disrupts the relationship which the alcoholic patient entertains with himself and others. This detachment is also manifested somatically via a tendency to feel less pain. Isolation progressively becomes total. Fouquet (1963) stresses that this state may be temporary; the author explains that when alcohol intake stops, the resumption of the psychogenic dynamic parallels the exit from solitude. Rainaut (1973) further describes a two-phase solitude: the first phase ranges from pleasure to anxiety. In the time of pleasure, solitude feels golden and peaceful. Alcohol works as a psychotropic. Intoxication leaves the memory of an ideal place, far from others. In the time of anxiety, the alcoholic patient is mostly concerned with isolating himself in order to return to this dream land. In the second phase, solitude becomes darkness. The psychotropic effects of alcohol fade, and the subject loses control over his consumption. He severs all links with the world, his self-image falters, and his body begins to wane. Consuming alcohol becomes his only quest, and his survival is predicated upon it. His environment disintegrates (couple, family, children, work, and finances). The subject reaches the apex of solitude. Rainaut (1973) emphasizes the notion that, to renounce alcohol, the subject must first exit his solitude.

Solitude must therefore be considered as a gradual withdrawal into oneself. This withdrawal is implemented via the addiction to a protective behavior against suffering, and which is indifferent to personal circumstances (single, in couple, social and professional relationships, etc.) or problems. Alcohol consumption becomes a solitary (even amongst people) self-medicating process whereby one may disinhibit, express or forget oneself. This conduct soon prevails as the core value of one's behavior. Getting drunk becomes the only solution and sole occupant of the psychogenic space, isolating the individual from his personal and professional environment, fostering short- and long-term careless behaviors. Only when the quest for intoxication becomes intolerable and the problems related to it exceed its benefits can the subject articulate a call for help. Now struggling, the alcoholdependent subject is forced to modify his habits and revamp his value systems in order to remain abstinent over a period of time. Nevertheless, even if the desire for change is manifest and significant, remaining abstinent is tied to a gradual exit from the feeling of solitude. Accordingly, providing and engaging in early support are critical, as is maintaining it over the long term (Boulze et al., 2010); indeed, for an undetermined, unassured and hesitant subject, this engagement is most often defined by forward and backward steps. It is therefore necessary to establish a network of referring partners, who will ceaselessly work to create new links toward the outside world, new relationships, etc.

In this domain, support groups for alcohol-addicted subjects are "natural" partners: their mission is to welcome anyone suffering from alcohol addiction as well as their relatives, and to provide the support and the motivation to stop drinking and remain abstinent. Relying on their close ties with medical resources, support groups can intervene at various stages of the therapeutic process, prior to or during the institutional detox stage. As explicitly stated in the Consensus Conference on the support modalities of alcohol-dependent subjects post detox (Conférence de Consensus, 2001), joining a support group is a critical component of long-term abstinence.

Research on this topic has shown that the impact of support efforts on abstinence is only statistically significant for subjects who attend meetings regularly (Gossop et al., 2003; Gossop et al., 2008). However, since most investigations were not prospective, their results must be analyzed with caution; furthermore, the definition of the judgment criterion (resumption of alcohol intake) varies with each investigation; finally, no specific account has been given of the strength of the social relationships at play.

The latter typically depends on individual values. Whether consciously or not, these values influence shortterm decisions and long-term projects. Accordingly, since individual satisfaction is a function of the level of expression of those values in everyday life, it is important to ensure that one's own values or those of others do not cause unmanageable conflicts. The aid provided by support groups not only fosters the ability to devise future life projects, but also allows subjects to familiarize themselves with the process of communicating and interacting, while defending personal positions (Boulze, 2004). Meetings help subjects learn to apply those new communication skills, thereby facilitating social integration. The act of renouncing alcohol may only be viable if the alcohol-dependent subject is able to come out of the isolation he has been confined to for so long. According to Rainaut (1973), this overwhelming transition is possible only when the alcoholic subject feels he can rely on appropriate support, whichever its source (group, medical caretaker, etc.). This initial "effective warmth" gently 
leads the subject toward a therapeutic space, on the condition that he shall not be judged, nor alcohol deemed a vice, a lack of will, or even bad habits. Rainaut (1973) insists on the human dimension value in prolonged abstinence, as a means to create a rightful place for the alcoholic subject, and for the latter to similarly invite the other into an exchange, thereby gradually coming out of isolation. Support groups allow the alcoholic subject to meet those who can welcome and actually hear him, by fostering a process of identification with support group members and the sharing of personal experiences (Remy-Ferraro Chantal, 2007).

Thus, the subject's involvement with speech groups may lead him to break the sphere of solitude and restore social links, thusly modifying so-called "interpersonal" values, which significantly condition human behavior (Allport et al., 1960; Fromm, 1959; Gordon, 1960). However, relapse, which is frequent after detox, can disrupt this process.

To study these phenomena in detail, we carried out a participative study (Hugon \& Seibel, 1988) involving researchers and support groups for alcohol-dependent subjects. Our aim was to analyze the evolution of interpersonal values after the cessation of alcohol intake over the course of one year and as a function of continued abstinence (or relapse).

\section{Method}

\subsection{Subjects}

Our participants were volunteers, recruited from 6 French support organizations for alcohol-dependent subjects (Alcooliques anonymes, Alcool Assistance, Alcoolécoute joie et santé, Croix Bleue, Les amis de la santé, Vie libre). The following inclusion criteria were set: male or female; age equal or greater than 18 years; new member in a group, or returning member after at least 1 year of total absence; gave consent for the use of a personal phone number for the purposes of this research; gave participation consent.

Participation was offered to all the volunteers who met the above criteria within 2 months after initial contact. The study's programmed length was one year.

\subsection{Materials and Procedure}

Alcohol consumption variables were collected and validated by the support groups, who administered both an initial questionnaire and a follow-up survey.

The initial questionnaire provided baseline information on the participants. It was administered by support group personnel, who collected general information (age, sex, verification of selection criteria match) and alcohol consumption-related information (number of detox/post-detox programs followed; date of last drink, cessation treatment modalities, first contact with a support group; craving intensity). Last, socio-demographic data were collected (lifestyle, professional activity, socio-professional category).

The follow-up survey was administered by a telephone investigator. First, items collected included relapse information (date, quantity, frequency), or in the case of prolonged abstinence, a self-assessment of alcohol craving by the subject. Second, the survey gathered group membership data (number of contacts, attendance), or if the subject had stopped going to sessions, reasons for this defection. Third and last, to end the interview, the investigator inquired if the subject was receiving medical or psychological follow-up treatment.

Interpersonal values (IVs) were assessed using Gordon's Survey of Interpersonal Values (SIV; Gordon, 1979). This instrument comprises 30 questions grouped under 6 independent and equally relevant value scales, designed to measure one's adaptability to the personal, social, marital and professional dimensions of one's life (Table 1).

Each question contains 3 proposals. It is aked to which proposal the subject agrees the best (2 points) and the less ( 0 point); the remaining proposal is scored 1 point. The scores obtained on all the questions within a value category are totaled and then are weighted through a correction sheet provided with the questionnaire (Gordon, 1975), yielding an overall category score which indicates the desirability assigned by the subject to the assessed value. There are 5 desirability levels (norm references): extremely high ( $\mathrm{T}>65)$; high $(56 \leq \mathrm{T} \leq 65)$; moderate $(46 \leq \mathrm{T} \leq 56)$; low $(36 \leq \mathrm{T} \leq 45)$; extremely low $(\mathrm{T} \leq 35)$.

Within 15 days following inclusion in the study, participants were contacted by telephone by an experienced SIV investigator, who administered the baseline summary questionnaire (M0).

The follow-up survey was carried out every 3 months (M3, M6, M9 and M12) over the course of one year. At each evaluation point, the investigator contacted the subjects by telephone, and administered both the alcohol summary questionnaire and Gordon's SIV. 
Table 1. SIV categories.

\begin{tabular}{lll}
\hline Category & Code & Meaning \\
\hline Support & S & Being treated with kindness and understanding. \\
Conformity & C & Doing what is socially accepted, conforming to social rules. \\
Recognition & R & Being looked up to, attracting favorable notice and praise, being important. \\
Independence & I & $\begin{array}{l}\text { Having the right to do whatever one chooses to, being free to make one’s } \\
\text { own decisions. }\end{array}$ \\
Benevolence & B & Doing things for other people, helping others, being charitable to others. \\
Leadership & L & Being in charge of people, having authority over them. \\
\hline
\end{tabular}

\subsection{Statistical Analyses}

The data collected were entered in a spreadsheet software. The anonymity of the subjects and of the support groups involved was respected. Quantitative variables were described using the mean \pm standard deviation or median, and were compared using the Student's t-test or Wilcoxon's test in the case of non-Gaussian distribution; items collected at various times were assessed with a repeated measures ANOVA. Quantitative variables were analyzed in terms of frequency and compared using the chi-squared test or Fisher's exact test when necessary.

\section{Results}

\subsection{Sample Characteristics}

In total, 145 subjects were recruited. Their main characteristics are presented in Table 2 . The total sample included 74 males (59\%) and 59 females, with a mean age of $47 \pm 9.7$ years. Slightly more than half (53.7\%) of the participants lived alone, and $46.7 \%$ were steadily employed. Almost a third (30.3\%) of the subjects had stopped drinking by themselves, whereas $20.7 \%$ had done so with medical assistance and $49 \%$ had undergone detox. Initial contact with support groups had been made prior to the cessation of alcohol intake for $45 \%$ of the subjects. Two-thirds of them (67.2\%) stated that they were receiving medical or psychological treatment at the time of this study.

\subsection{Interpersonal Values}

Our results are presented in three steps. First, we describe the overall questionnaire results obtained at M0. Second, we present the results of the IV score variations of the subgroup which managed to complete the full term of the study, comparing the subjects who resumed alcohol consumption with those who remained abstinent. Third and last, we compare the IV scores at M0 to determine if, immediately upon cessation of alcohol intake, interpersonal values differ between those who remained abstinent and those who did not. We then interpret our results in light of desirability, as assessed with the T scores obtained on Gordon's SIV.

\subsubsection{Initial IV Summary (M0)}

Of the 145 participants, 8 quickly revoked their consent and did not respond to the SIV at M0. The analysis is therefore based on data gathered from a total of 137 subjects. Support, Recognition and Independence scores were within average ranges for both males and females (Table 3). However, males obtained significantly higher Conformity and Benevolence scores than females, whereas the opposite was obtained for Recognition. Conformity scores were average for males, and low for females. Benevolence scores were high for males and average for females. Last, Leadership scores were low amongst women, and lower still amongst men.

The scores on Conformity, Recognition, Benevolence and Leadership highlighted significant differences between males and females.

\subsubsection{Evolution of IV Scores over Time}

Fifty-three subjects (36.5\% of the sample) completed the study in its entirety, responding to both the SIV and the Alcohol information survey at each programmed time point. This subgroup was used to carry out a detailed 
Table 2. Main socio-demographic characteristics of the participants.

\begin{tabular}{cc}
\hline $\mathbf{N}$ & 145 \\
$\mathbf{M} / \mathbf{F}$ & $74 / 59$ \\
Age (m \pm sd) & $47 \pm 9$ \\
Living alone (\%) & 57.0 \\
Professional status (\%) & \\
Actively employed & 51.0 \\
Not employed & 49.0 \\
Cessation of alcohol intake (\%) & \\
By oneself & 30.3 \\
As in-patient & 49.0 \\
As out-patient & 20.7 \\
Contact with the self-help support group (\%) & \\
Before cessation of consumption & 45.0 \\
During cessation of consumption & 23.9 \\
After cessation of consumption & 31.0 \\
Medical or psychological support & 67.2 \\
\hline
\end{tabular}

Table 3. Interpersonal value scores according to sex.

\begin{tabular}{|c|c|c|c|c|}
\hline & Total sample & Males & Females & $\boldsymbol{P}$ \\
\hline $\mathrm{N}$ & 137 & 68 & 49 & \\
\hline Support & $52.4 \pm 7.9$ & $52.6 \pm 8.1$ & $52.0 \pm 7.7$ & NS \\
\hline Conformity & $45.6 \pm 7.7$ & $47.8 \pm 7.3$ & $42.5 \pm 7.1$ & $<0.001$ \\
\hline Recognition & $5.9 \pm 11.0$ & $50.35 \pm 10.4$ & $54.1 \pm 11.6$ & 0.048 \\
\hline Independence & $50.6 \pm 8.0$ & $50.1 \pm 7.6$ & $51.3 \pm 8.4$ & NS \\
\hline Benevolence & $54.8 \pm 8.4$ & $56.5 \pm 7.6$ & $52.2 \pm 9.0$ & 0.002 \\
\hline Leadership & $41.2 \pm 9.2$ & $40.2 \pm 8.4$ & $42.5 \pm 10.1$ & 0.007 \\
\hline
\end{tabular}

analysis of the evolution of IV scores. The subgroup's baseline (initial summary at M0) scores were not significantly different than that of the subjects who did not complete the program. At each follow-up point (M3 through M12), more than $80 \%$ of the subjects stated that they attended group sessions regularly and had more than 10 contacts per month; thirty-seven (69.8\%) of them reported that they received regular medico-psychological support. Of the 53 subjects, twenty-eight (52.8\%) remained strictly abstinent over the course of the observation period, whereas twenty-five (47.2\%) resumed drinking alcohol in the same period, with no significant sex difference.

Figure 1 shows the scores' general trends. Dependence scores increased slightly at M3, but significantly decreased at M9 and M12. Conformity scores increased significantly from M0 to M12, while Recognition scores fell in the same period. Independence scores tended to increase, but this trend remained statistically insignificant. Benevolence scores remained stable over the observation period. After a significant drop at M3, Leadership scores progressively increased until reaching baseline values at M9, at which point they plateaued.

From a strict norm standpoint, Conformity received low-average to low $\mathrm{T}$ scores, while Leadership $\mathrm{T}$ scores remained systematically low.

\subsubsection{Impact of the Resumption of Alcohol Intake}

Alcohol consumption status (i.e., remaining abstinent or resuming intake) had little impact upon general score 


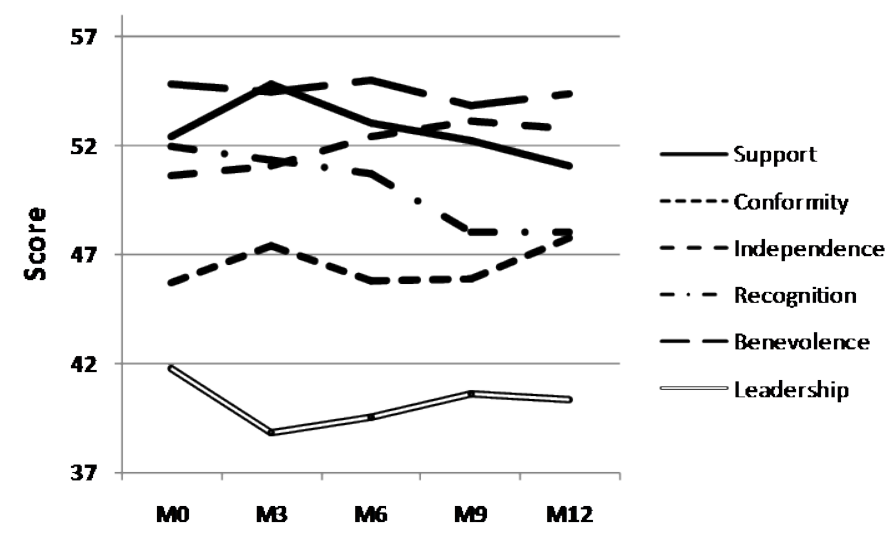

Figure 1. Evolution of IV scores of the 53 subjects who completed the one-year program.

trends over time, except for Conformity, which curve displayed a concave " $U$ " shape for abstinent subjects, and a convex one for relapse subjects (figure not shown)

Conversely, the trends observed seemed to be amplified in abstinent subjects. Indeed, the decrease in Dependence and Recognition scores and the increase of Conformity scores were only significant amongst abstinent subjects (Table 4); moreover, the increase trend of the Independence score of the 53 subjects became significant after stratification based on alcohol status. However, the Benevolence and Leadership score trends remained flat and unaffected by the resumption of alcohol intake. Scores evolved similarly for both males and females, and were not influenced by medical or psychological treatment.

In order to determine if one or more IV parameters were linked to relapse, we compared the value scores at baseline (M0) of those subjects who had resumed alcohol intake and those who had remained abstinent. Only one parameter differed between these two subgroups: Independence scores were significantly higher amongst relapse subjects, with no sex difference; a similar trend was observed in the subgroup of the 53 subjects who had completed the study in its entirety, though that difference was not statistically significant (Table 5).

\section{Discussion}

In the following discussion, we present our analysis of the main Interpersonal Value results, with a particular focus on their evolution over time.

The particularly low Leadership value scores across the entire subject population might correspond to a refusal to assume a position of authority. This withdrawal posture was more notably marked amongst men. Such reticence could be explained by fear or inhibition stemming from the degradation of a previous authority status (discredited by alcoholism)? In that case, self-help groups would play a protective role-thus explaining the relatively strong attendance to meetings.

Surprisingly for this population, the Support and Independence scores were within the average range at M0. Nonetheless, fluctuations appeared over time for the subjects who remained abstinent. On the other hand, the average scores for Conformity, Recognition and Benevolence were linked to a smoothing statistical effect, which can be elicited by distinguishing between sexes.

Indeed, upon inclusion and immediately after alcohol intake cessation, males and females differed on these three values (Conformity, Recognition and Benevolence), as well as on Leadership. Females seem to refuse to arrange their lives according to social conventions (alcohol-dependent women are heavily stigmatized); men, however, seem eager to engage in the support relationship. Our female subjects expressed a stronger desirability for Recognition than their male counterparts. According to our results, women have a tendency to seek consideration in order to be respected. Perhaps what they seek in support groups is for their difference to be heard, to be recognized by and amongst others (higher range of the Recognition average). Instead, men hope sharing their own experience will help others in the group.

In the following discussion, we present our overall analysis of the results. We first describe the constants which this analysis revealed, and then discuss category variations.

The systematically low leadership value scores illustrated a representative characteristic of alcohol-dependent 
Table 4. Evolution of IV scores between M0 and M12 for the 53 subjects who completed the follow-up program and remained abstinent or resumed alcohol consumption.

\begin{tabular}{ccccc}
\hline Group & IV & M0 & M12 & $\boldsymbol{P}$ \\
\hline \multirow{2}{*}{ Abstinence } & Support & $53.2 \pm 7.8$ & $49.3 \pm 10.2$ & 0.027 \\
& Conformity & $45.7 \pm 7.1$ & $49.4 \pm 8.2$ & 0.007 \\
& Recognition & $50.6 \pm 13.5$ & $44.7 \pm 7.8$ & 0.002 \\
& Independence & $49.0 \pm 8.3$ & $53,3 \pm 9.4$ & 0.012 \\
& Benevolence & $57.2 \pm 8.5$ & $56.1 \pm 9.5$ & NS \\
& Leadership & $42.1 \pm 9.1$ & $43.3 \pm 7.7$ & NS \\
\hline \multirow{2}{*}{ Relapse } & Support & $52.2 \pm 8.3$ & $52.9 \pm 8.2$ & NS \\
& Conformity & $45.0 \pm 8.7$ & $45.8 \pm 9.6$ & NS \\
& Recognition & $53.4 \pm 9.9$ & $51,8 \pm 9,7$ & NS \\
& Independence & $53.2 \pm 7.3$ & $52.0 \pm 10.6$ & NS \\
& Benevolence & $53.9 \pm 8.3$ & $52.3 \pm 11.5$ & NS \\
& Leadership & $39.1 \pm 8.3$ & $40.4 \pm 12.4$ & NS \\
\hline
\end{tabular}

IV parameters related to the resumption of alcohol intake.

Table 5. Baseline IV scores (upon inclusion) of abstinent and relapse subjects.

\begin{tabular}{cccc}
\hline & Abstinent subjects & Relapse subjects & $\boldsymbol{P}$ \\
\hline $\mathbf{N}$ & 54 & 65 & \\
Support & $53.4 \pm 7.8$ & $51.3 \pm 7.6$ & NS \\
Conformity & $45.0 \pm 6.7$ & $45.1 \pm 8.8$ & NS \\
Recognition & $52.2 \pm 12.4$ & $51.4 \pm 10.5$ & NS \\
Independence & $48.9 \pm 7.8$ & $52.7 \pm 7.7$ & 0.02 \\
Benevolence & $55.7 \pm 7.8$ & $54.6 \pm 9.0$ & NS \\
Leadership & $42.2 \pm 8.2$ & $41.3 \pm 9.3$ & NS \\
\hline
\end{tabular}

people (regardless of their current consumption status), who shun positions of leadership when asking for help. First and foremost, at that moment, alcoholic subjects are intent on being helped themselves.

Subjects who remained abstinent between M0 and M12 and those who resumed drinking in that same period can only be distinguished on the basis of Independence. The results for this value were unexpected: relapse subjects gave it an average initial score, which did not change over time. Conversely, abstinent subjects placed greater and greater importance on their independence (scores started from the lowest end of the range at M0, and finished at the higher end of the average at M12). This value had initial low desirability, and evolved in parallel with abstinence. This evolution may be interpreted as an effect of self-help group participation, which reinforces one's desire to make one's own decisions.

Over the course of one year, the most significant variations were observed in abstinent subjects, who exhibited fluctuating rapports with interpersonal values (4 out of the 6 IVs received significantly evolving scores). At M12, abstinent subjects preferred to receive less understanding (Support value). They eventually placed little or moderate importance on abiding by social conventions (Conformity value). Lastly, they seemed determined in their resolve to offer support to others but also to shun any position of authority and managing others (Leadership value). The value they placed on helping each other appeared to be paramount in their ability to proceed out of isolation. This realization was paralleled by the cessation of alcohol intake. Belonging to a support group seemed to have afforded them protection by allowing them to help others as well. More than any other processes, this membership may have had a critical impact on the prolongation of abstinence. The spirit of mutual aid, evidenced at the onset of the study, may have contributed to regular and genuine exchanges within the groups. 
Another key result is the inertia of IV scores in our relapse subjects. These individuals seemed to refuse to follow social conventions (Conformity) and to assume any authority over others (Leadership). Clearly, their position was one of retreat and of rejection of social norms. We surmise that this corresponded to a reaction to a feeling of being at the fringe, of being cast aside. This reaction was likely based on a dynamic of oppositions. Thus, in spite of the positive reinforcement received within the support group, these subjects failed to use the experience of others to reset their own. Nonetheless, strong attendance to group sessions seemed to have mitigated this withdrawal behavior.

We conclude by discussing our results at M12. As seen above, we believe that attending group sessions regularly helped abstinent subjects develop a dynamic of exit from isolation. Indeed, we observed that, from a psychological standpoint, these subjects' interpersonal values were modified. Relapse subjects, however, still faced the challenge of isolation. Although they were able to avoid being marginalized thanks to group membership, they were unable to implement a salutary psychological dynamic.

The main underlying teaching of this study is that actual psychological changes are taking place as early as in the first year of abstinence. On the other hand, alcoholic subjects' rapport with values does not evolve without the cessation of alcohol intake. We may then accept the reversibility of isolation as presented in the literature, as long as it is accompanied by the cessation of alcohol consumption.

This work's hypothesis is therefore partially validated: Membership in a support group appears linked with the sharing of values, but this sharing leads to behavior modifications amongst abstinent subjects only. The IVs of an abstinent subject may in fact be modified. Nonetheless, the challenge of isolation remains difficult to define. On the one hand, subjects — whether they remain abstinent or resume drinking - benefit from the protection provided by support group membership (against the risk of marginalization); on the other hand, after a year of group participation, the support process does not guarantee the actual re-instatement of a social link. Our results particularly illustrate the latter for relapse subjects. But this process was apparent in our abstinent subjects as well, who preferred to evolve within the re-assuring confines of their groups (which operated as micro-societies). This retreat into the protection zone of the group is observed by group personnel as well. Over time, the phenomenon becomes less pronounced, as group members find new interests outside of the group.

\section{Conclusion}

In conclusion, we believe this study evidenced the merit of membership in a support group over time, regardless of whether subjects stop drinking or not. In future works, researchers should attempt to verify if commitment to a support group is greater than the reliance on medico-psycho-social treatment programs. In our study, we found that groups provide a sense of community outside of the realm of social conventions, thereby allowing alcoholdependent subjects to develop a loyalty to them. In turn, groups adapt to the angst of members, who are led to share personal experiences with others who are experiencing or have experienced similar life challenges. The resulting connections among group members aid the development of longer-term, warm and structuring relationships. Subjective exchanges between members can help articulate the empathetic sharing of identity rebuilding (modeled after the experience of co-members as former users). These exchanges only lead to behavior changes when they are associated with abstinence. With prolonged abstinence, attending meetings regularly seems to facilitate a restorative psychological process which eventually yields hope-filled values. We postulate that the recovery of autonomy (Independence) is predicated on the acceptation of an allegiance to the support group. This allegiance enables subjects to come out of isolation by facilitating the entrance into an exchange process. Yet, for this process to succeed, a preliminary movement of retreat within the group must be experienced by subjects, so that the group's recognition may serve as a uniting thread around the sharing of common ideals (Kaës, 2005). Only then may the question of otherness and the difference with others be addressed. That is precisely the topic of the phenomenological approach (Chafetz, 1975), which stresses the fact that "the strategies of alcohol addiction maintenance strongly suggest that our patients' relational dynamic should be fostered within group therapy” (Pringuey, 2005: p. 773). Hemerneutics-inspired therapies should therefore offer an “us-ness” ("nostrité”, in French; Pringuey, 2001), i.e., a relational structure capable of restoring the "us”, thereby allowing the alcoholic subject to "return to the party, as if powerfully and fiercely-though artificially and solitarily-leveraged by the addictive behavior” (Pringuey, 2005: p. 773).

To further this work, it would be interesting to assess subjects over longer terms (e.g., two to three years of abstinence). Indeed, the complexity of the challenges faced by alcohol-dependent subjects (social context, professional situation, family relationships, etc.) evolves over long periods of time. Admittedly, we only witnessed 
the beginnings of the psychological changes associated with a year of abstinence. Studying them over a longer period would allow researchers to determine the nature of those transformations.

\section{Acknowledgements}

This research was made possible by the combined support of the French Interministerial Mission for the Fight Against Drugs and Addictive Behaviors (Mission Interministérielle de Luttecontre la Drogue et les conduits addictives) and the Paul Valéry University of Montpellier, France, provided within the framework of the research priorities outlined in the French Government 2013-2017 plan for consumption cessation.

\section{Conflict of Interests}

None.

\section{References}

Allport, G. W., Vernon, P. E., \& Lindzey, G. (1960). Study of Values (3rd éd. rev.). Boston: Houghton Mifflin.

Boulze, I. (2004). The Support Group, a Way to Break the Isolation and to Strengthen the Solidarity. Alcoologie et Addictologie, 26, 36S-41S.

Boulze, I., Launay, M., \& Bruère-Dawson, G. (2010). The Word and the Structuring of the Subjective Experience with the Alcoholic Subject. L'Evolution Psychiatrique, 75, 199-211. http://dx.doi.org/10.1016/j.evopsy.2010.04.003

Chafetz, M. (1975). Alcoholism and Alcoholic Psychosis. In: A. M. Freedman, H. I. Kaplan, \& B. J. Sadock (Eds.), Comprehensive Textbook of Psychiatry (pp. 1131-1348). New York: William et Wilkins.

Conférence de Consensus (2001). Modalities of the Support of Alcoholic Subjects after a Weaning. Haute Autorité de Santé, Paris. http://www.has-sante.fr/portail/display.jsp?id=c_271905

Fouquet, P. (1963). The Apsychognosia. Alcoologie et Addictologie, 22, 57S-61S.

Fromm, E. (1959). Value, Psychology, and Human Existence. In A. H. Maslow (Ed.), New Knowledge in Human Values (pp. 151-164). New York: Harper \& Row.

Gossop, M., Harris, J., Best, D., Man, L. H., Manning, V., Marshall, J., \& Strang, J. (2003). Is Attendance at Alcoholics Anonymous Meetings after Inpatient Treatment Related to Improved Outcomes? A 6-Month Follow-Up Study. Alcohol and Alcoholism, 38, 421-426. http://dx.doi.org/10.1093/alcalc/agg104

Gossop, M., Stewart, D., \& Marsden, J. (2008). Attendance at Narcotics Anonymous and Alcoholics Anonymous Meetings, Frequency of Attendance and Substance Use Outcomes after Residential Treatment for Drug Dependence: A 5-Year Follow-Up Study. Addiction, 103, 119-125. http://dx.doi.org/10.1111/j.1360-0443.2007.02050.x

Gordon, L. V. (1960). Survey of Interpersonal Values. Chicago: Science Research Associates.

Gordon, L. V. (1975). The Measurement of Interpersonal Values. Chicago, IL: Science Research Associates.

Gordon, L. V. (1979). Manual Inventory of Interpersonal Values. Paris: E.C.P.A.

Hugon, M.-A., \& Seibel, C. (1988). Recherches impliquées, Recherches action: Le cas de l'éducation. Belgique: De Boeck Université.

Kaës, R. (2005). Internal Groups and Psychic Groupality: Genesis and Issues of a Concept. Revue de Psychothérapie Psychanalytique de Groupe, No. 45, 9-30.

Pringuey, D. (2001). “Usness” in Alcoholism. Art du Comprendre, 2, 122-135.

Pringuey, D. (2005). A Phenomenology of Alcohol Addiction. A Primordial Experience of “Usness”. Evolution Psychiatrique, 70, 771-779. http://dx.doi.org/10.1016/j.evopsy.2005.10.004

Rainaut, J. (1973). Chronology of the Alcoholic Real-Life Experience. (AREAT). http://www.appel-arlon.net/telech/jean_rainaut.pdf

Remy-Ferraro, C. (2007). A Time to Speak Freely within a Certain Group Setting for Former Alcoholics. Revue de Psychothérapie Psychanalytique de Groupe, No. 49, 201-214. 